\title{
Lipid peroxidation during chronic inflammation
}

Sokolovska Irina ${ }^{\mathrm{a}}$, Nechiporenko Valentina ${ }^{\mathrm{b}}$, Gordiyenko Natalia ${ }^{\mathrm{b}}$, Pozdnyakova Olena $^{\mathrm{b}}$, Volkova

Svitlana $^{\mathrm{b}}$, Cymbal Victor ${ }^{\mathrm{c}}$, Makurina Galina $^{\mathrm{a}}$

Department of Hygiene and depatment of Biochemistry, Zaporizhzhya State Medical

University, avenue Mayakovsky 26, Zaporizhzhya 69035, Ukraine

${ }^{a}$ Zaporizhzhya State Medical Universityz, ${ }^{b}$ Khorticky National Academy, ${ }^{c}$ Zaporozhye Public

Engineering Academy

irinasokol10@meta.ua

Keywords: free radicals, chronic inflammation, oxidative stress, anti-and prooxidant systems, physiological systems.

To keep needed level of peroxide lipid oxidation is necessary for the normal functioning of physiological systems. It is supported by the balance of anti-and prooxidant systems. The positive influence of lipid peroxidation processes in the organism is manifested by the restoration of the composition and maintenance of the properties of biological membranes, participation in energy processes, cell division, synthesis of biologically active substances. It has been established that the inflammatory process is accompanied by changes in lipid metabolism and the intensity of peroxide oxidation.

\section{Introduction}

At the present stage of the development of society, the state of health of the Ukrainian nation, especially reproductive, is characterized by a low birth rate against a high level of the main component of the threat of reproduction of a person, and it's an infertility. Each year in the reproductive age in our country it comes about 300 thousand of adolescents, the harmonious development of which largely determines the state of their reproductive potential.

Chronic inflammatory diseases of the genitalia significantly affect the health of million people with childbearing age. Chronic inflammation is characterized by protracted, often eroded course, susceptibility to relapse, complications and resistance to the therapy. Violations of reproductive health of women and men are most likely to result in sexually transmitted infections. These diseases are revealed in all age groups. In our country, the official figures for the frequency of this disease don't reflect the real situation. There are several reasons for this: firstly, the poverty of the health system, which can no longer exercise full control over the health of the population. 
Secondly, the steady increase in the number of commercial medical centers offering "anonymous treatment of all diseases with a $100 \%$ guarantee". Thirdly, the attitude of the population towards their own health, which our citizens aren't used to follow.

Health is a social value, well-known for everyone. There is a lot of dependence on the health of the male population of Ukraine: the conception of a healthy child, a harmonious family, working capacity, a man's life expectancy (unfortunately, Ukrainian men live for 7-10 years less than women).

Actually, the problem of inflammatory diseases of the genitalia, especially caused by sexually transmitted infections, increases with every year [1]. These diseases are among the most common in the general structure of infectious pathology and present a serious medical, social and demographic danger [2].

The etiological factor of chronic nonspecific inflammatory diseases of the genital organs is the bacterial flora - (3-83\% of cases), including gonococcus (up to $30 \%$ ), trichomonas di (5-85\%), chlamydia (30-60\%), mycoplasma and ureaplasma (91-100\%), viral infections (30\%), mushrooms (1-30\%). But most cases of chronic non-specific inflammatory diseases of the genital organs are caused by mixed infections. Most of them are gonococci and trichomonias, garnevals and trichomonias, mushrooms and viruses, mushrooms and chlamydia, etc. [3].

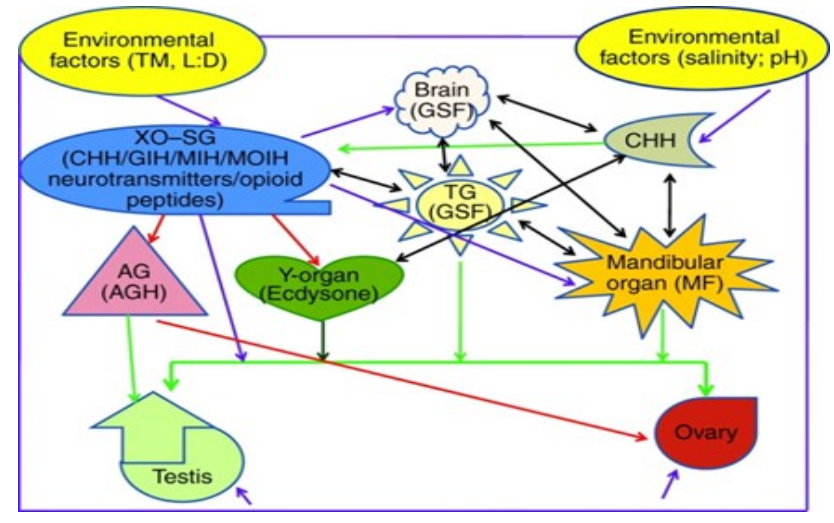

Figure 1. Scheme of destruction of the body by nonspecific inflammatory diseases

In modern medicine during the examination of the patients with chronic nonspecific inflammatory diseases, the development of severe complications requiring a new strategy and methods from the physician, a new view on the diagnosis and treatment of these diseases [4].

In immune-inflammatory processes, lipid imbalance arises, which is most likely to be caused by an imbalance of pro- and antioxidant systems and / or by other mechanisms that play a major pathogenetic role in the development of endothelial dysfunction and a large number of diseases and pathologies [5].

The growth of lipid indicators (total cholesterol, triglycerides, low density lipoprotein cholesterol, malondialdehyde) often occurs in clinically healthy individuals with age.

In recent decades, researchers have paid great attention to the process of inflammation and associated immune and non-immune mecha-noses as one of the factors for the development and further progression of 
atherosclerosis [6]. Atherosclerosis is considered by them as an immune-inflammatory process that runs through the type of hypersensitivity reaction of the detained type, in which antigenic stimuli emanate from modified lipids [7].

That was also revealed data about the major role of leukocytes in atherogenesis and progression of coronary heart disease [8]. The production of active metabolites by leukocytes, their significant adhesion to the vascular endothelium and subsequent transdotal ulcer migration may be the beginning of the formation of an atherosclerotic plaque.

There is an oxidative modification of lipoproteins of nis-density. Against the background of hypercholesterolemia and dyslipidemia, autoaggression increases, and the level of circulating immune complexes increases. Modified low density lipoprotein overexpresses monocytic macrophages. They are a key proatherogenic factor. Absorption of low density lipoprotein by monocytes leads to the formation of "pony" cells, their accumulation in the walls of the vessels with subsequent necrosis, the formation of lipid bands, plaques, atherosum.

Consequently, dyslipidemia and elevated levels of low density lipoprotein cholesterol are considered to be a major risk factor for atherosclerotic inflammation.

Chronic immune fibrous inflammation is considered as an important factor in the development and progression of atherosclerosis and coronary disease against the background of elevated cholesterol levels of low density lipoprotein [9].

Many authors point to the ability of vitamin $A$ to regulate lipid peroxidation processes. The presence of conjugate bonds in the vitamin A molecule and the propensity to auto-oxidation justify the possibility of its participation, the ability to reduce the activity of NADP and ascorbate-peroxidation in liver microsomes, inhibit microsomal lipid oxidation, and others.

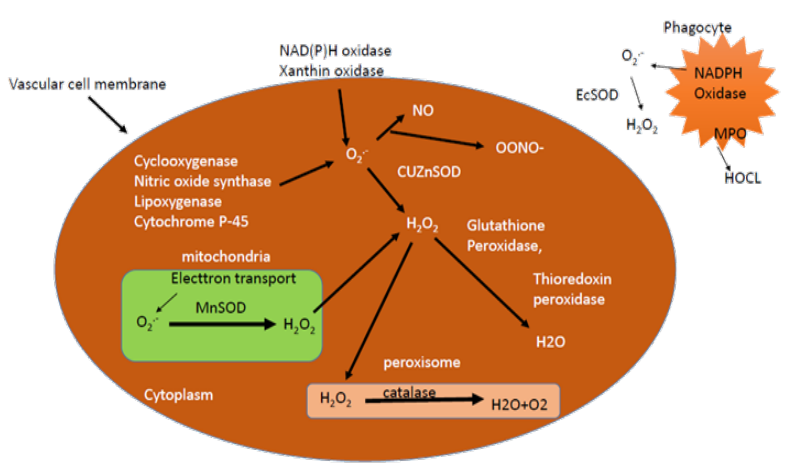

Figure 2. Action of antioxidant enzymes system

The enhancement of phagocyte release of activated forms of oxygen (AFO) and its interaction with polyunsaturated fatty acids during inflammation activates peroxide lipid oxidation.

A certain low level of peroxide oxidation of lipids is necessary for the normal functioning of physiological systems [10]. It is supported by the balance of anti-and prooxidant systems. The positive influence of lipid peroxidation processes on a living organism is manifested by 
the restoration of composition and maintenance of the properties of biological membranes, participation in energy processes, cell division, synthesis of biologically active substances. Lipid acids in the blood of various lipids, which are transferred to the cells by specific transport proteins of apolipoproteins, form lipidtransporting protein macromolecules. Peroxide lipid oxidation occurs in the blood in the phase section: the aqueous medium - lipid in the lipids. In low density lipoprotein, activated forms of oxygen are oxidized, mainly unsaturated fatty acids with different amounts of double bonds.

The antioxidant protection system (AOPS) is a collection of enzymatic and nonenzymatic factors that protect the cell from free radicals that have been formed [11].

Antioxidant enzymes include superoxide dismutase, which catalyzes oxygen dismutase into hydrogen peroxide, glutathione reductase, glutathione peroxidase, ceruloplasmin and catalase, which decomposes hydrogen peroxide into water and oxygen molecules [12]. The nonenzymatic system of AOPS includes fat-soluble ( $\alpha$-tocopherol, ubiquinone, naproquinone, carotenoids, creatinides, steroid hormones, including estrogens, etc.) and water soluble (sodium thiosulfate, glutathione, ascorbic acid, citric and nicotinic acid) substances. Also among the natural antioxidants are a group of proteins, which includes thiol groups (cysteine, methionine, etc.). Antioxidants are able to inhibit free radical oxidation by binding free radicals and their transformation products.

Catalase is a ferriferous hemoprotective enzyme responsible for catabolism of hydrogen peroxide.

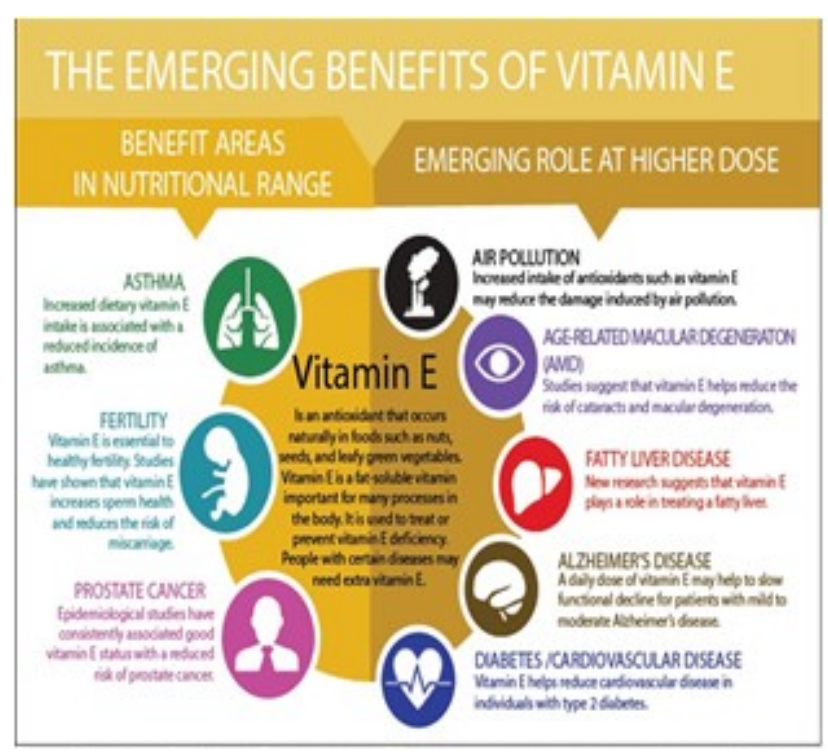

Figure 3. Helth benefits of vitamin $\mathrm{E}$ at the traditional RDA intake range and emerging research areas at higher levels. Figure courtesy of DSM National Products.

It is proved that the oxygen molecule is not aggressive in relation to the living cell. At the same time, active forms of oxygen (hydrogen peroxide, hydroxyl radical, superoxide anion radical, singlet oxygen) are formed by enzymatic or non-enzymatic methods, as well as lipoperoxidation products initiated by them, are toxic [13]

\section{Formation of "oxidative stress"}

Among the primary mechanisms of cell damage during oxidative stress, the oxidation of lipid acid residues in membrane phospholipids leads. This reduces their hydrophobicity and 
violates the stability of membranes, changes the work of membrane-bound enzymes, increases the permeability of membranes for ions.

The interactions of free radicals with lipid acids are widely known due to their relevance in the food industry. The appearance of an unpleasant smell and rancid food - this is a manifestation of lipid peroxidation.

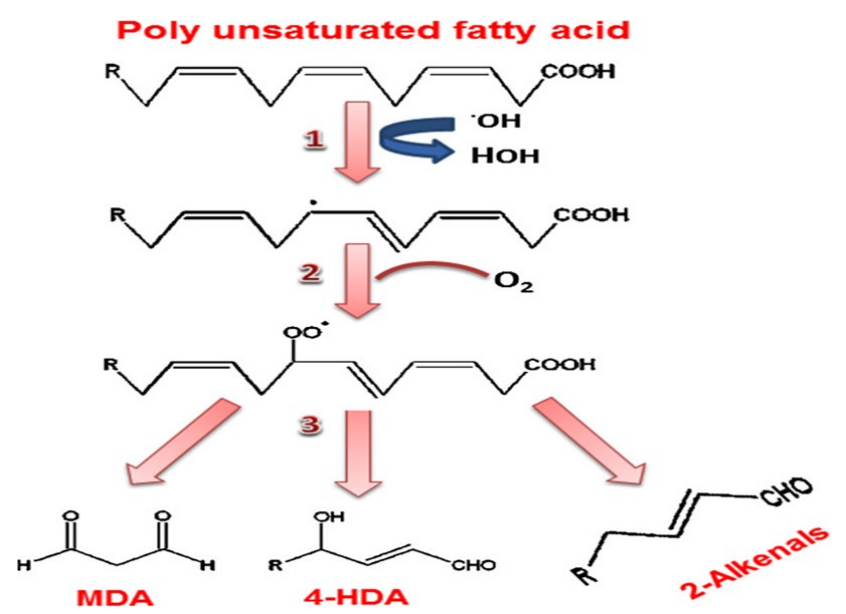

Figure 4. Redox reactions

The main substrate for free-radical reactions are the double bonds of polyunsaturated lipid acids. In cell membranes, polyunsaturated lipid acids are found in phospholipids and glycolipids.

A large amount of phospholipids with polyunsaturated lipid acids is localized in the membrane of high, low and very low density lipoproteins [20].

It is known that peroxide oxidation of lipids can occur in two ways: non-enzymatic ascorbate-dependent, which is activated by ions of metals of variable valency, and enzymatic NADP - dependent.
Superoxide anion radical is formed during the intermediate recovery of oxygen by enzymes in the transport of electrons along the respiratory chain of mitochondria and the redox system of the endoplasmic reticulum, as well as by the autooxidation of various intracellular components of oxyhemoglobin, NADH, glutathione, flavin, cytochrome $\mathrm{C}$, ascorbic acid, adrenaline, sulfhydryl compounds

The two-electron recovery of oxygen leads to the formation of hydrogen peroxide. Non-enzymatic oxygen dismutation under certain conditions can produce singlet oxygen, which, without being free radical, has high activity.

Oxygen can also react with hydrogen peroxide to form a highly active hydroxyl radical.

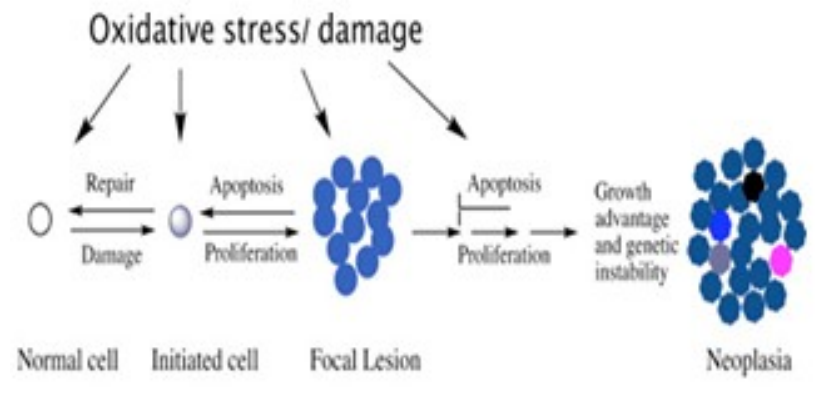

Figure 5. Neoplasia development process

It is how oxidative stress occurs. However, the chain of peroxide oxidation of lipids can break even at the activation stage (inactivation of active forms of oxygen), and at the stage of formation of hydroperoxides of lipids. According to some authors [14], in the 
state of oxidative stress, attacks, in the first place, are not lipids, but proteins of plasma membranes, which leads to their depolymerization and cell lysis.

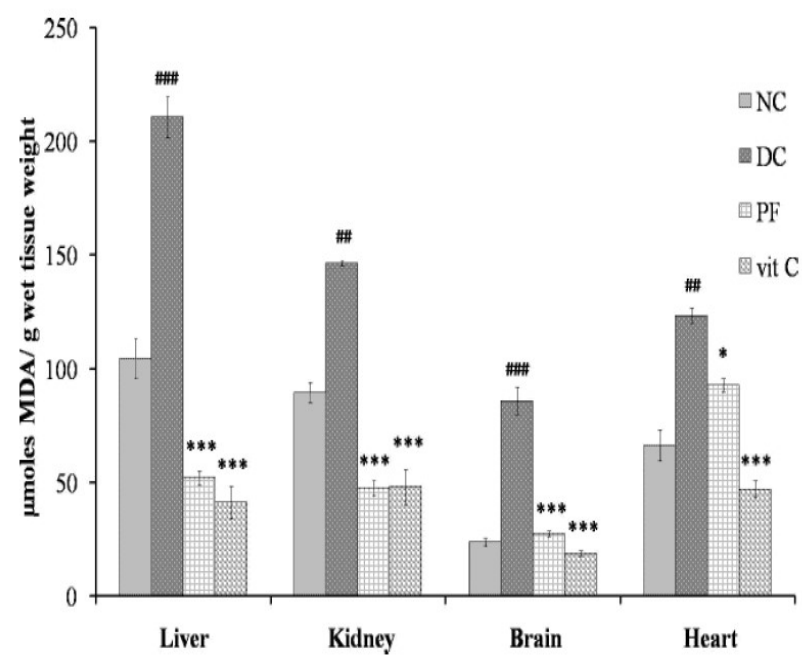

Figure 6. Effects of metanolic extract of $P$. fulgens and vitamin $\mathrm{C}$ on the lipid peroxidation.

In last years, it has been proved that peroxide oxidation is a physiological stage of inflammation, part of the biological function of maintaining the "purity" of the internal environment of a multicellular organism. The production and secretion of PCT cells by activated forms of oxygen is a stage of the systemic inflammatory response syndrome. Activation of the synthesis of cells by antioxidant enzymes (superoxide dismutase, glutathione peroxidase, catalase) is part of the compensatory anti-inflammatory defense syndrome in which the neuroendocrine system is involved.

Among the primary products of peroxidation of oxidation of lipids are diane conjugates, triene, oxidienic, tetraene conjugates. By the end products of peroxide oxidation of lipids - malonic dialdehyde, schiff bases, pigments.

Under the influence of LPO, it is changed the structural and functional organization of biomembranes changes, causing changes in the effector and regulatory functions of immunocompetent cells. The severity of LPO and the depletion of AOS are closely related to the degree of immune disorders. [21]

In patients with increased respiratory tract infections and bronchial asthma [15], pyelonephritis [16], prostatitis [17], there is a certain relationship between the state of immunity and lipid peroxide oxidation and the activity of enzymes in the antioxidant system. Quite clear changes in the activity of peroxide lipid oxidation and antioxidant defense systems have been identified in many infectious and inflammatory diseases [18].

The relationship between the state of immunity and the indexes of peroxide lipid oxidation and the activity of enzymes of the antioxidant defense system is also established in patients with non-infectious diseases: atherosclerosis, coronary heart disease, hypertension, obesity, diabetes mellitus, malignant tumors, allergic diseases [19], and others.

The lipid peroxidation processes contribute to increasing the viscosity and orderliness of the lipid bichlor, change the phase 
properties of the membranes and reduce their electrical resistance, and also limit the exchange of phospholipid molecules between two monolayers (such as the called flip flop). With peroxidase processes, oppression of membrane proteins is observed. At the cellular level, free radical lipid oxidation is accompanied by edema of mitochondria, by separation of oxidative phosphorylation, solubilization of membrane structures.

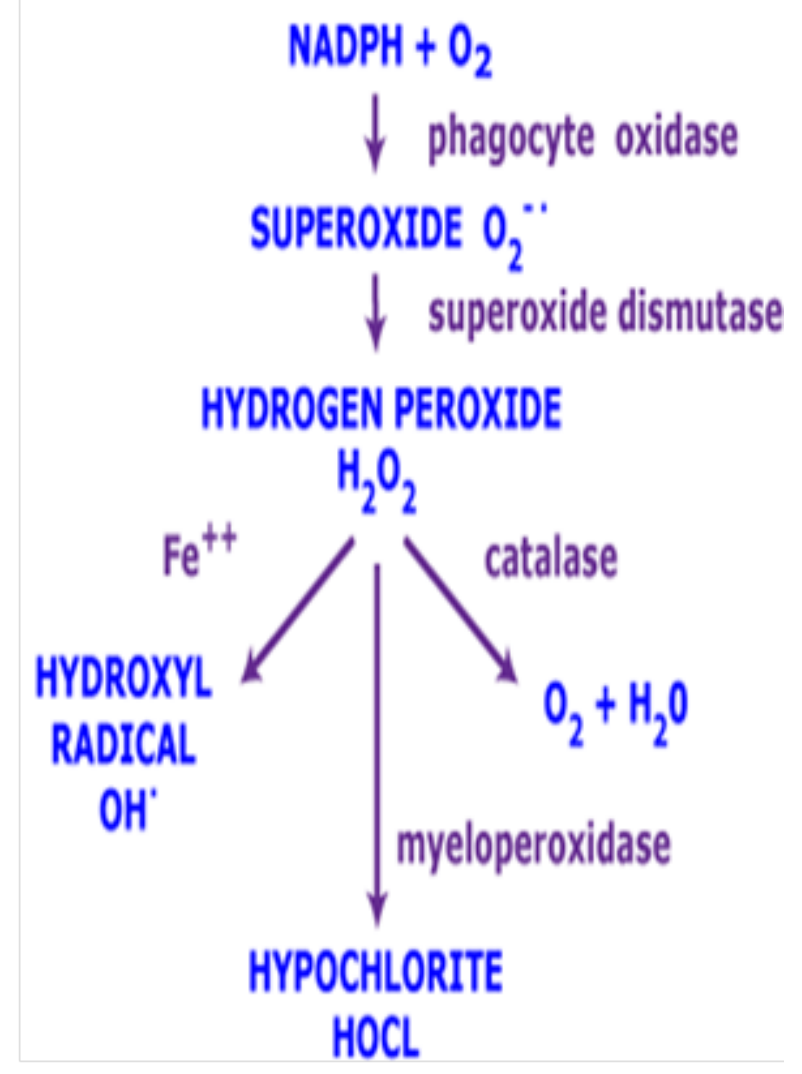

Figure 7. Nadph oxidase superoxide dismutase

Active forms of oxygen significantly change the physical and chemical properties of the membrane of endothelial cells by reducing the number of double bonds in polyene lipid acids of phospholipids and fragmentation of integral proteins of membrane receptors and carriers. Protoolysis in lysosomes of sedentary macrophages completes the process of inflammation - the removal of endogenous and exogenous pathogens by the cells of the loose connective tissue. In the denaturation of pathogens, the development of autoantibodies to pathological oxidized epitopes of apo-100 low density lipoproteins also matters. Under the action of activated forms of oxygen there is a covalent interaction between them and secondary products of apo-100 and the formation of pathological epitopes. These epitopes are determined by immunocompetent cells as "antigenic determinants", initiation of the development of autoantibodies to endogenous pathogens and the formation of immune complexes.

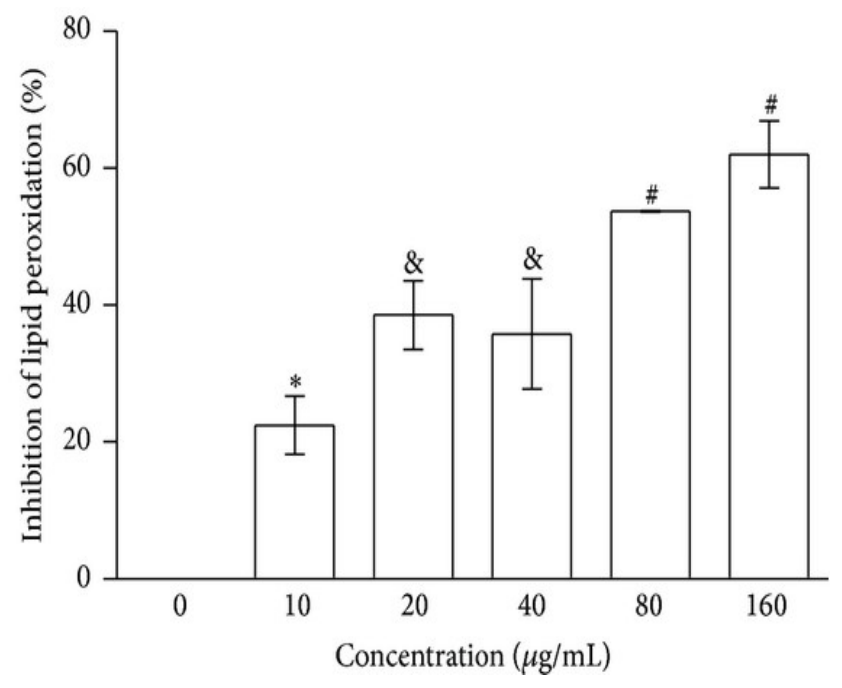

Figure 8. The physical therapy group

\section{Experimental part}

\section{Material and methods}

The examination was performed on 95 practically healthy persons - 50 men $(\mathrm{M}), 45$ 
women (W) of the control group (C) and 162 patients with CND of 18-50 years old. Biochemical methods of research were carried out in the accredited clinical and diagnostic laboratory "ZMAPO".

Concentration of general X-ray was determined by spectrophotometry using a set of reagents of the firm "Philitis Diagnostics", Dnipropetrovsk. The presence of chylomicrons (CM) and cholesterol-LLD were determined by visual evaluation of the sample after exposure to blood plasma at a temperature of $0^{\circ}-+4^{\circ} \mathrm{C}$, LLD cholesterol concentrations by the Burstein and Samaya methods, and the concentration of HDL-HDL using a set of reagents from the firm Cormay, TG using the set of reagents "Lahema", Czech Republic. Verification of diagnoses regarding DLP was conducted in accordance with medical guidelines for the diagnosis of cardiovascular disease [MI Lutaya, 2003, D. Fredricson, WHO, 1970]. The intensity of the LPO was evaluated at the concentration of MDA by reaction with thiobarbituric acid [A.I. Karpishchenko, 1999].

\section{Results and discussion}

The character of dislipoproteinemia in patients with chronic inflammatory process of genital organs

In studying lipids of the spectrum of blood plasma of patients with chronic nonspecific inflammatory diseases of the genital organs, significant differences with the corresponding indices of clinically healthy persons were found. Concentration of total cholesterol in the blood plasma of patients in the third group in 1,2 times $(\mathrm{p}<0,05)$ was higher than in the control (Table 1).

It should be noted that the increase in the concentration of cholesterol in the blood plasma in sick women and men, occurred in accordance with the increase in middle-aged patients in groups, while in $\mathrm{K}$ this was not observed. The visual determination of the presence of chylomicrons in blood plasma in patients of both sexes of groups 2 and 3 was significantly higher ( 9 out of 58 and 10 out of 54) in the control (1 out of 35). The incidence of cases when the visually determined presence of cholesterol - very low density lipoprotein in the plasma of blood of sick women and men in group 1 (5 out of 64) tended to increase, and in patients 2nd (12th out of 58th) and 3rd ( 22 out of 44) groups it was significantly higher ( $p$ $<0.05$ ) than in the control ( 1 out of 30 and 0 out of 35). The level of low density lipoprotein cholesterol-lipoprotein in the blood plasma of women of the 1st and 2nd groups tended to increase, and in women of the 3rd group it was 1.4 times higher $(p<0.05)$ than in the control.

It is essential that the content of lowdensity lipoprotein cholesterol-lipoproteins in women's blood plasma increased correspondingly with the increase in middle age in the group. There was no shift in the 
concentration of low density cholesterollipoproteins in the blood plasma of male patients. In patients of the 3rd group, the decrease in the concentration of high-density lipoprotein cholesterol-lipoproteins in the plasma was 1.4 times $(p<0.05)$. In patients of men of all three age groups, no significant changes were found on the part of LPHD.

The concentration of triglycerides in the blood plasma of sick women increased as the average age increased. In patients of women of the 2nd and 3rd groups this increase was significant (in 1,3 times $(p<0,05)$.In patients of men of group 2, the concentration of triglycerides in blood plasma increased by 1.2 times $(p<0.05)$ compared with men K. In patients of group 3 this increase was also significant in 1.3 times $(\mathrm{p}<0.005)$.

Table 1. Lipid plasma spectrum of patients with chronic non-specific inflammatory diseases of the genitalia compared with donors

\begin{tabular}{|l|l|l|}
\hline Group & \multicolumn{1}{|c|}{$\begin{array}{c}\text { Triglycerides mmol.1- } \\
\text { Cialaldide mmol.1- } \\
\text { C1 }\end{array}$} & $\begin{array}{c}\text { Malonium } \\
\text { dias }\end{array}$ \\
\hline & $1,25 \pm 0,07$ & $3,88 \pm 0,31$ \\
\hline C2 & $1,23 \pm 0,5$ & $3,18 \pm 0,36$ \\
\hline & $1,27 \pm 00,7$ & $4,02 \pm 0,38$ \\
\hline C3 & $1,35 \pm 0,12$ & $3,21 \pm 0,33$ \\
\hline & $1,33 \pm 0,15$ & $4,0 \pm 0,34$ \\
\hline 1 & $1,29 \pm 0,09$ & $3,26 \pm 0,30$ \\
\hline & $1,45 \pm 0,15$ & $4,92 \pm 0,21^{*}$ \\
\hline 2 & $1,42 \pm 0,08$ & $3,84 \pm 0,33$ \\
\hline & $1,62 \pm 0,12^{*}$ & $6,41 \pm 0,73^{*}$ \\
\hline 3 & $1,58 \pm 0,06^{*}$ & $5,23 \pm 0,44^{*}$ \\
\hline & $1,68 \pm 0,05^{*}$ & $6,47 \pm 0,71^{*}$ \\
\hline & & $5,93 \pm 0,62^{*}$ \\
\hline
\end{tabular}

\begin{tabular}{|c|c|c|c|c|}
\hline Group & \multicolumn{2}{|c|}{$\mathrm{CMn}$} & LPVLD n & $\begin{array}{l}\text { LPLD } \\
\text { mmol1-1 }\end{array}$ \\
\hline \multirow[t]{2}{*}{$\mathrm{Cl}$} & M & 0 & 0 & $3,42 \pm 0,29$ \\
\hline & $\mathrm{F}$ & 0 & 0 & $2,83 \pm 0,37$ \\
\hline \multirow[t]{2}{*}{$\mathrm{C} 2$} & M & 0 & 0 & $3,85 \pm 0,40$ \\
\hline & $\mathrm{F}$ & 0 & 0 & $3,09 \pm 0,27$ \\
\hline \multirow[t]{2}{*}{ C3 } & M & 0 & 0 & $3,69 \pm 0,32$ \\
\hline & $\mathrm{F}$ & 0 & 0 & $3,31 \pm 0,29$ \\
\hline \multirow[t]{2}{*}{1} & M & 0 & 2 & $3,90 \pm 0,31$ \\
\hline & $\mathrm{F}$ & 0 & 3 & $3,34 \pm 0,61$ \\
\hline \multirow[t]{2}{*}{2} & M & $4^{*}$ & $5^{*}$ & $4,17 \pm 0,55$ \\
\hline & $\mathrm{F}$ & $5^{*}$ & $9^{*}$ & $3,90 \pm 0,38$ \\
\hline \multirow[t]{2}{*}{3} & M & $5 *$ & $12 *$ & $4,12 \pm 0,44$ \\
\hline & $\mathrm{F}$ & $5^{*}$ & $10^{*}$ & $4,49 \pm 0,23 *$ \\
\hline
\end{tabular}

\begin{tabular}{|c|l|l|l|}
\hline Group & \multicolumn{1}{|c|}{ LPLD } & \multicolumn{1}{|c|}{ LPHD } & Cholesterole \\
& mmol.1-1 & \multicolumn{1}{|c|}{ mmol.1-1 } & mmol.1-1 \\
\hline C1 & $3,42 \pm 0,29$ & $1,35 \pm 0,11$ & $4,70 \pm 0,51$ \\
\hline & $2,83 \pm 0,37$ & $1,33 \pm 0,14$ & $4,13 \pm 0,41$ \\
\hline C2 & $3,85 \pm 0,40$ & $1,40 \pm 0,15$ & $5,20 \pm 0,54$ \\
\hline & $3,09 \pm 0,27$ & $1,37 \pm 0,13$ & $4,52 \pm 0,38$ \\
\hline C3 & $3,69 \pm 0,32$ & $1,75 \pm 0,20$ & $5,45 \pm 0,43$ \\
\hline & $3,31 \pm 0,29$ & $1,40 \pm 0,29$ & $4,60 \pm 0,33$ \\
\hline 1 & $3,90 \pm 0,31$ & $1,32 \pm 0,18$ & $5,25 \pm 0,58$ \\
\hline & $3,34 \pm 0,61$ & $1,60 \pm 0,14$ & $4,99 \pm 0,32$ \\
\hline 2 & $4,17 \pm 0,55$ & $1,28 \pm 0,19$ & $5,45 \pm 0,44$ \\
\hline & $3,90 \pm 0,38$ & $1,44 \pm 0,05$ & $5,44 \pm 0,62$ \\
\hline 3 & $4,12 \pm 0,44$ & $1,20 \pm 0,07$ & $5,32 \pm 0,47$ \\
\hline & $4,49 \pm 0,23 *$ & $1,02 \pm 0,12^{*}$ & $5,51 \pm 0,45^{*}$ \\
\hline & & & \\
\hline
\end{tabular}

Notes.

$1 \mathrm{n}$ - the number of positive results;

$2 *-\mathrm{p}<0,05$, the reliability of the differences compared with the control group

During the analysis of the features of the types of dislipoproteinemia in the subjects, it 
was determined that in patients with male $1 \mathrm{st}$ (youngest) age groups, the presence of dislipoproteinemia was found to be quite frequent, mainly in type 11a and in individual cases - 11 and 111 types (Table 2).

In patients of women of the 1 st group, isolated cases of dislipoproteinemia IIa, II and 111 types were found, which are associated with very high atherogenicity. In patients with men of group I, II (type I) dislipoproteinemia was observed significantly ( 7 out of 22$)(p<0.05)$ than women (I out of 38), which is probably due to a sufficiently high estrogen saturation of the body of women aged 18-28 years dislipoproteinemia of IIa type (18 out of 58) was found more frequently in both men and women of the 2nd group (middle-aged) than in control $(0)(p<0.05)$, and in isolated cases dyslipoproteinemia II $\mathrm{b}$ and the third types. In some cases, there was also a dislipoproteinemia in the type, and in women it was significantly more frequent $(5$ out of 28$)(p<0.05)$ than in group I and control (0).
Table 2. Features of the types of dislipoproteinemia in patients with chronic nonspecific inflammatory diseases of genital organs.

\begin{tabular}{|r|l|r|r|}
\hline \multicolumn{2}{|c|}{ Group } & $\begin{array}{c}\text { Number } \\
\text { of } \\
\text { people } \\
\text { in one } \\
\text { group }\end{array}$ & $\begin{array}{c}\text { Number of people } \\
\text { without } \\
\text { dislipoproteinemia }\end{array}$ \\
\hline \multirow{2}{*}{ C } & males & 50 & 50 \\
\cline { 2 - 4 } & females & 45 & 45 \\
\hline \multirow{3}{*}{1} & males & 22 & 12 \\
\cline { 2 - 4 } & females & 38 & 33 \\
\hline \multirow{2}{*}{2} & males & 30 & 13 \\
\cline { 2 - 4 } & females & 28 & 12 \\
\hline \multirow{2}{*}{3} & males & 22 & 2 \\
\cline { 2 - 4 } & females & 22 & 5 \\
\hline
\end{tabular}

\section{Number of people}

with dislipoproteinemia

\begin{tabular}{|c|c|c|c|c|}
\hline $\begin{array}{c}\text { IIa } \\
\text { type }\end{array}$ & $\begin{array}{c}\text { IIв } \\
\text { type }\end{array}$ & III type & $\begin{array}{c}\text { IV } \\
\text { type }\end{array}$ & $\begin{array}{c}\mathrm{V} \\
\text { type }\end{array}$ \\
\hline- & - & - & - & - \\
\hline- & - & - & - & - \\
\hline $7^{*}$ & 2 & 1 & - & - \\
\hline $1^{*}$ & 3 & 1 & - & - \\
\hline 11 & 2 & 1 & - & 3 \\
\hline $7^{*}$ & 3 & 1 & - & $5^{\wedge}$ \\
\hline $3^{*}$ & $7^{*}$ & $5^{*}$ & - & $5^{\wedge}$ \\
\hline $3^{*}$ & $5^{*}$ & 3 & 2 & $4^{\wedge}$ \\
\hline
\end{tabular}

Notes:

1. * - $\mathrm{p}<0,05$ the reliability of the differences, in comparison with the control

2. ${ }^{\wedge}-\mathrm{p}<0,05$ in comparison with the control group and group number 1. 
In patients of women of the 2nd and $3 \mathrm{rd}$ groups and in male patients of all groups there was a significant increase in the level of malondialdehyde: in men of group 1 in 1,3 times $(\mathrm{p}<0,05)$, and in the 2nd and 3rd groups, groups - in 1,6 times; in women of the 2 nd and 3rd groups - 1.6 times $(\mathrm{p}<0.05)$.

In the 3rd group of patients (the oldest by age) the following was found. Dyslipoproteinemia of type IIa was significantly lower $(6$ out of 44$)(p<0,05)$ compared with patients in the 2 nd group (18 out of 58) among men and women.

At the same time, more often than in the control revealed dislipoproteinemia of IV (12 of 44 ) and III ( 8 of 44 ) types of both men and women of the 3rd group.

Type $\mathrm{D}$ dislipoproteinemia in the 3rd group of patients was significantly more frequent $(9$ out of 44$)(p<0.05)$ than in the 1 st group and control (0). Two women in this group also found type IV dislipoproteinemia.

The analysis of the number of patients with hypercholesterolemia (GCS), depending on gender and age, showed the following (Table 3).
Table 3. The frequency of hypercholesterolemia, depending on the gender and age of the patients.

\begin{tabular}{|c|c|c|c|}
\hline \multirow{4}{*}{ Group } & \multicolumn{3}{|c|}{ Number of examined patients } \\
\hline & \multicolumn{3}{|c|}{ males } \\
\hline & \multirow{2}{*}{$\begin{array}{l}\text { Common } \\
\text { number }\end{array}$} & \multicolumn{2}{|c|}{$\begin{array}{c}\text { with } \\
\text { hypercholesterolemia }\end{array}$} \\
\hline & & $\begin{array}{c}\text { With } \\
\text { adequate } \\
\text { number of } \\
\text { CS }\end{array}$ & $\begin{array}{l}\text { With } \\
\text { high } \\
\text { number } \\
\text { of CS }\end{array}$ \\
\hline 1 & 28 & 5 & 3 \\
\hline 2 & 30 & $20 *$ & 3 \\
\hline 3 & 25 & 12 & 4 \\
\hline
\end{tabular}

\begin{tabular}{|c|c|c|c|}
\hline \multirow{4}{*}{ Group } & \multicolumn{3}{|c|}{ Number of examined patients } \\
\hline & \multicolumn{3}{|c|}{ females } \\
\hline & \multirow{2}{*}{$\begin{array}{l}\text { Common } \\
\text { number }\end{array}$} & \multicolumn{2}{|c|}{$\begin{array}{l}\text { with } \\
\text { hypercholesterolemia }\end{array}$} \\
\hline & & $\begin{array}{c}\text { With } \\
\text { adequate } \\
\text { number of } \\
\text { CS }\end{array}$ & $\begin{array}{l}\text { With } \\
\text { high } \\
\text { number } \\
\text { of CS }\end{array}$ \\
\hline 1 & 36 & 11 & 1 \\
\hline 2 & 30 & 9 & 2 \\
\hline 3 & 29 & 9 & 1 \\
\hline
\end{tabular}

Note. ${ }^{*}-\mathrm{p}<0,05$ in comparison with all other groups;

Consequently, we found an increase in the frequency of the definition of dislipoproteinemia, including dislipoproteinemia with high atherogenicity, in accordance with the increase in age of patients. The number of patients with hypercholesterolemia in all age groups was the same and consisted of: subnormal cholesterol (29 out of 95) and high cholesterol (4 out of 105). Among men of the 1st (youngest age 
group) hypercholesterolemia with subnormal cholesterol levels was found to be less likely ( 5 out of 28) for all other groups.

The incidence of hypercholesterolemia with subnormal cholesterol in the 2nd (20th in 30 th) and 3rd (12th of 25th) men's groups significantly exceeded this in group 1, and hypercholesterolemia with high cholesterol in all groups of men was the same and exceeded that for women.

Among the reasons for the high frequency of hypercholesterolemia in men, especially the 2nd group, along with the way of life and nutrition can be sexually transmitted infections.

An analysis of changes in the lipid metabolism indices in the groups of patients with chronic non-specific inflammatory diseases of the genital organs caused by different pathogens has been carried out (Table 4).

Table 4. Lipid plasma spectrum of patients with chronic non-specific inflammatory diseases of genital organs with different types of infections

\begin{tabular}{|c|c|c|c|}
\hline Group & CMn & LPVLDn & $\begin{array}{c}\text { LPLD } \\
\text { mmol.1- }\end{array}$ \\
\hline C & 0 & 0 & $45,3 \pm 0,6$ \\
\hline 1 & 2 & 4 & $48,5 \pm 0,4$ \\
\hline 2 & 2 & 3 & $46,9 \pm 3,2$ \\
\hline 3 & $4^{*}$ & $11^{*}$ & $51,4 \pm 3,7$ \\
\hline 4 & $4^{*}$ & $5^{*}$ & $49,3 \pm 3,1$ \\
\hline 5 & 3 & $6^{*}$ & $49,3 \pm 3,2$ \\
\hline 6 & $4^{*}$ & $10^{*}$ & $50,2 \pm 3,1$ \\
\hline
\end{tabular}

\begin{tabular}{|c|c|c|c|}
\hline CS & LPHD & TH & MDA \\
mmol.1-1 & mmol.1-1 & mmol.1-1 & mmol.1-1 \\
\hline $3,28 \pm 0,19$ & $\begin{array}{c}1,62 \pm 0,1 \\
1\end{array}$ & $\begin{array}{c}1,21 \pm 0,01 \\
*\end{array}$ & $\begin{array}{c}5,22 \pm 0,2 \\
3\end{array}$ \\
\hline $\begin{array}{c}4,8 \pm 0,43 * \\
1,46 \pm 0,1 \\
7\end{array}$ & $\begin{array}{c}1,63 \pm 0,33 \\
*\end{array}$ & $\begin{array}{c}7,28 \pm 1,6 \\
2 *\end{array}$ \\
\hline $\begin{array}{c}4,77 \pm 0,35 \\
*\end{array}$ & $\begin{array}{c}1,38 \pm 0,1 \\
1 *\end{array}$ & $1,7 \pm 0,29 *$ & $\begin{array}{c}7,26 \pm 0,5 \\
*\end{array}$ \\
\hline $\begin{array}{c}5,12 \pm 0,51 \\
*\end{array}$ & $\begin{array}{c}1,33 \pm 0,1 \\
3 *\end{array}$ & $\begin{array}{c}1,86 \pm 0,27 \\
*\end{array}$ & $\begin{array}{c}7,49 \pm 0,5 \\
3 *\end{array}$ \\
\hline $\begin{array}{c}5,03 \pm 0,35 \\
*\end{array}$ & $\begin{array}{c}1,75 \pm 0,1 \\
3\end{array}$ & $\begin{array}{c}1,66 \pm 0,34 \\
*\end{array}$ & $\begin{array}{c}7,81 \pm 1,1 \\
8 *\end{array}$ \\
\hline $\begin{array}{c}5,09 \pm 0,47 \\
*\end{array}$ & $\begin{array}{c}1,46 \pm 0,1 \\
3\end{array}$ & $\begin{array}{c}1,69 \pm 0,28 \\
*\end{array}$ & $\begin{array}{c}7,53 \pm 1,3 \\
2 *\end{array}$ \\
\hline $\begin{array}{c}5,19 \pm 0,49 \\
*\end{array}$ & $\begin{array}{c}1,35 \pm 0,1 \\
4 *\end{array}$ & $1,7 \pm 0,37 *$ & $\begin{array}{c}7,79 \pm 1,4 \\
9 *\end{array}$ \\
\hline
\end{tabular}

Notes:

1. $\mathrm{n}$ - the number of positive results

2. * $-\mathrm{p}<0,05$ the reliability of differences compared with $\mathrm{K}$

Concentration of total cholesterol in all groups of patients was probably in $(1,1-1,6)$ times higher than in the control.

The highest level of cholesterol was observed in persons of the 6th group, which revealed a mixed microflora in genital brush strokes. Chylomicromelemia was detected in all groups of patients more frequently than in control, with differences in 3rd (4th in 30th), 4th (4th in 28th) and 6th (4th in 41th) groups.

The incidence of cases of visually detecting very low density lipoprotein cholesterol in groups 3rd and 6th increased significantly, especially in 3rd (11th out of 30th) and 6th (10th in 41) groups compared to control. 
The concentration of low-density lipoprotein cholesterol-lipoproteins in patients with chronic non-specific inflammatory diseases of genital organs did not differ significantly from such control. The concentration of high-density lipoprotein cholesterol-lipoprotein in the blood plasma of patients in the $2 \mathrm{nd}, 3 \mathrm{rd}$ and 6 th groups was lower by 1.2 times $(\mathrm{p}<0,05)$ from that in the control. The level of malondialdehyde in patients in all groups was likely to be 1.4 to 1.5 times higher than those in control subjects.

The concentration of triglycerides in the blood plasma of patients with chronic nonspecific inflammatory diseases of the genital organs has significantly increased, on average, 1.4 times.

Consequently, the increase in total cholesterol, triglycerides and malondialdehyde did not differ in the various sexually transmitted infections. However, very low density proatherogenic lipoprotein cholesterol is more often found in groups with chlamydial, viral and most frequent - with fungal and mixed flora. At the same time, the level of anti - atherogenic high-density lipoprotein cholesterol decreased in the groups of patients with defeat of trichomonads, fungi and mixed flora.

In analyzing the peculiarities of the types of dislipoproteinemia in patients with different types of infection, it was found that type II dislipoproteinemia occurs more frequently than in the control group, especially in the 4th (7th of 28th) and 5th (5th of 19th) groups with chlamydial and a viral infection. Dislipoproteinemia II was more common in patients 2 nd (4th of 26 th), 3rd (4th of 30 th), 6th (6th of 41st) and most often 4th (7 of 28) groups (Table 5). The probable increase in cases of type III dislipoproteinemia was found in the 1st group of patients (4 out of 36). Regarding the dislipoproteinemia of the IV and V types, no significant differences with the control were detected.

Thus, the incidence of detection of atherogenic dislipoproteinemia in the amount of patients with chronic non-specific inflammatory diseases of genital organs is significantly higher than in the control, but did not differ significantly between groups of patients with different types of inflammatory process activators.

Table 5. Features of the types of dislipoproteinemia in patients with chronic non-specific inflammatory diseases of genital organs with different types of infection

Number of people with dislipoproteinemia

\begin{tabular}{|l|l|l|}
\hline \multicolumn{1}{|c|}{ III } & \multicolumn{1}{c|}{ IV } & \\
& & \\
\hline- & - & - \\
\hline $4 *$ & - & 2 \\
\hline 2 & - & 2 \\
\hline 3 & 1 & 3 \\
\hline- & 1 & 4 \\
\hline- & - & 3 \\
\hline 3 & - & 3 \\
\hline
\end{tabular}




\begin{tabular}{|c|c|c|c|}
\hline \multirow{2}{*}{ Group } & \multirow{2}{*}{$\begin{array}{l}\text { Amount } \\
\text { of } \\
\text { persons } \\
\text { in the } \\
\text { group }\end{array}$} & \multicolumn{2}{|c|}{$\begin{array}{l}\text { Number of people with } \\
\text { dislipoproteinemia }\end{array}$} \\
\hline & & IIa & ІІв \\
\hline $\mathrm{C}$ & 95 & - & - \\
\hline 1 & 36 & $6^{*}$ & $2 *$ \\
\hline 2 & 26 & $4^{*}$ & $4^{*}$ \\
\hline 3 & 30 & $4^{*}$ & $4 *$ \\
\hline 4 & 28 & $7 *$ & $5^{*}$ \\
\hline 5 & 19 & $5^{*}$ & 2 \\
\hline 6 & 41 & $6^{*}$ & $5 *$ \\
\hline
\end{tabular}

hypercholesterolemia with subnormal cholesterol levels, and in patients with chlamydial flora with high cholesterol levels.

Table 6. Frequency of detection of hypercholesterolemia in groups of patients with chronic non-specific inflammatory diseases of genital organs with different types of infection

\begin{tabular}{|c|c|c|c|}
\hline \multirow{2}{*}{ Group } & $\begin{array}{c}\text { Common } \\
\text { number } \\
\text { in a } \\
\text { group }\end{array}$ & \multicolumn{2}{|c|}{$\begin{array}{c}\text { Number of people with } \\
\text { hypercholesterolemia }\end{array}$} \\
\cline { 3 - 4 } & & $\begin{array}{c}\text { With } \\
\text { adequate } \\
\text { number of } \\
\text { CS }\end{array}$ & $\begin{array}{c}\text { With } \\
\text { adequate } \\
\text { number } \\
\text { of CS }\end{array}$ \\
\hline 1 & 36 & 12 & 2 \\
\hline 2 & 26 & 9 & 1 \\
\hline 3 & 30 & $14^{*}$ & 2 \\
\hline 4 & 28 & 8 & 3 \\
\hline 5 & 19 & $8^{*}$ & 1 \\
\hline 6 & 41 & $18^{*}$ & 4 \\
\hline
\end{tabular}
(14 out of 30) fungal flora, 5th (8 out of 19) with viruses and 6th (18th out of 41) mixed flora groups, compared with 1 (12 out of 36) with bacterial flora groups.

The highest incidence of high-level cholesterol was in the 4 th (3 out of 28) chlamydial and 6th (4 out of 41) and mixed flora groups. According to the total assessment the frequency of hypercholesterolemia in 3-6 groups can be suspected of an increased risk of atherogenesis in these groups. Some differences in the influence of fungal, chlamydial and viral flora on the frequency of hypercholesterolemia have been found. Patients with fungal and viral flora were the most commonly observed

Note. ${ }^{*}-\mathrm{p}<0,05$, in comparison with the 1 st group.

Thus, as a result of the conducted studies, an increase in the frequency of visual detection of chylomycorans, very low density cholesterol-lipoproteins, an increase in the content of low density cholesterol-lipoproteins, triglycerides, malonic dialdehyde, a decrease in the concentration of cholesterol - high density lipoprotein, triglycerides, in patients with chronic non-specific inflammatory genital disease.

In the patients of both sexes, the direction of the shift of certain indicators was the same. It can be concluded that the degree of 
these shifts was increased in line with the increase in middle-aged patients in the groups.

The revealed dyslipidemia, dislipoproteinemia and increased peroxide lipid oxidation were mostly atherogenic. In addition, an increase in total cholesterol and malonic dialdehyde in patients of all groups with different infections, a decrease in high cholesterol-lipoprotein cholesterol levels in patients with Trichomonas vaginalis, fungal and mixed flora, an increase in the incidence of atherogenic type dislipoproteinemia and hypercholesterolemia in all groups indicate an increased risk atherogenesis in patients with chronic non-specific inflammatory diseases of genital organs.

Consequently, chronic non-specific inflammatory process in the genital organs can play a role in the development of dislipoproteinemia and peroxide oxidation of lipids and the development of atherosclerosis.

To solve this issue, the data of lipid metabolism indices were compared, which characterize inflammatory processes: local ones - in the center of inflammation (genital organs), as well as in the system of circulating blood.

\section{Conclusions}

So, the enhancement of peroxide lipid oxidation is accompanied by an increase in the formation of prostanoids, leukotrienes, which leads to changes in vascular reactivity, violation of the vascular permeability, and increased aggregation capacity of platelets. It also matters in the development of many diseases.

\section{References}

[1] Adaskevich VP. Sexually transmitted diseases. - Vitebsk: edit. Vitebsk medical university; 2014, p.310

[2] Gus'kov AR, Yacevich GB, Turna AA. Laboratory monitoring of aspirate in transurethral drainage of the prostate gland in patients with chronic obstructive prostatitis. Urology 2011, pp.15-20.

[3] Mavrov GI, Unuchko SV, Bondarenko GM. Dermatology and Venereology 2004, pp.67-71.

[4] Abu Ebeyn Ahmad Mohamed. Clinicoimmunological and pharmacological aspects in the local treatment of chronic prostatitis. Urologiia 2003, pp.66-68.

[5] Wang P, Xie K, Wang C, Bi J, . Oxidative Stress Induced by Lipid Peroxidation Is Related with Inflammation of Demyelination and Neurodegeneration in Multiple Sclerosis. European Neurology 2014;72(34):249-254

[6] Bazhenova NG. The role of the lipid spectrum of membranes in the violation of the superficial architectonics of erythrocytes in patients with malignant neoplasms, Tomsk; 2014, pp.20-30.

[7] Moore K, Tabas I. Macrophages in the Pathogenesis of Atherosclerosis. Cell 2011;145(3):341355.

[8] Ilyenko LN, Ivanova EV. Evaluation of the effectiveness of the use of the drug Enterosgel in the complex treatment of recurrent forms of nonspecific vaginitis. Art of treatment 2014, pp.84-85.

[9] Beregova OG, Krivohac'kaya YO, Lankina IO, Dolgopolova IA, Elizarova LI. Laboratory general clinical and microcytoscopic examination for the disease of female genital organs and mammary gland. Educational and methodical manual, Zaporizhzhzya 2006, pp.164-165 
[10] Titov VN, Lysicin DM, Amelushkina DM. Double bonds of fatty acids, alcohols, glycerin, cholesterol and non-polar serum lipids. Diagnostic value of hypercholesterolemia 2012, pp.7-11.

[11] NEUBAUER R. Free radicals and antioxidants. The Lancet 1994;344(8934):1440-1442.

[12] Garvey E, Oplinger J, Furfine E, Kiff R, Laszlo F, Whittle B, Knowles R. 1400W Is a Slow, Tight Binding, and Highly Selective Inhibitor of Inducible Nitric-oxide Synthasein Vitroandin Vivo. Journal of Biological Chemistry 1997;272(8):4959-4963.

[13] Yin G, Wang Y, Cen X, Yang M, Liang Y, Xie Q. Lipid Peroxidation-Mediated Inflammation Promotes Cell Apoptosis through Activation of NF- $\mathrm{BB}$ Pathway in Rheumatoid Arthritis Synovial Cells. Mediators of Inflammation 2015;2015:1-10.

[14] Orosz CG. Endothelial activation and chronic allograft rejection, Clin. Transplant 1994;8(3 Pt 2):299-303.

[15] Ambunin VG, Zakharin AK. Conjugation of changes in catecholamines, thiol compounds and lipid peroxidation in bronchial asthma; 2011, pp.63-66.

[16] Savchenko RP, Gordyushina IV. Effect of oxidative stress on platelet activation in patients with renal pathology; 2004, pp.48-51.

[17] Suvorov AP. Correction of violations of antioxidant protection in chronic prostatitis by millimeterwave electromagnetic radiation; 2001, pp.39-41.

[18] Kondakova AP. Intensity of the processes of lymphocyte membrane lipid peroxidation and oxidative modification of plasma proteins in patients with urogenital chlamydiosis; 2014, pp.24-28.

[19] Dmytryakov VA. The role of thiotriazoline in the complex treatment of children with dysplastic forms of congenital renal malformations: Zaporizhzhya; 1997, pp.39-41.

[20] Kumagai T, Matsukawa N, Kaneko Y, Kusumi Y, Mitsumata M, Uchida K. A Lipid Peroxidation-derived Inflammatory Mediator. Journal of Biological Chemistry 2004;279(46):48389-48396.
[21] Wood L, Gibson P, Garg M. Biomarkers of lipid peroxidation, airway inflammation and asthma. European Respiratory Journal 2003;21(1):177-186. 